\title{
Toward Development of a Visual Arts Diagnostic Achievement Test: Issues and Concerns
}

$$
\text { Robert Sabol }
$$

With the rise of the excellence in education movement of the 1980s, evaluation of educational progress emerged as an issue of importance. Local school districts and state departments of education began examining educational programs in order to determine the degrees of progress being made by learners in various disciplines. Several states began developmental programs to provide information which lead to suggestions for state-wide improvement of education. The need for assessment in the fine arts was seen as an essential component of a comprehensive education evaluation program.

One state involved in developing an education assessment program is Indiana. Having been a visual arts classroom teacher for eighteen years, I became involved with the assessment program when asked to involve students in the developmental process. My involvement increased as the program creation of the Indiana Department of Education Proficiency Guide (Indiana Department of Education, 1987). The Proficiency Guide contains listings of proficiencies for all subject disciplines, including visual arts. The visual arts portion of the guide contains listings of proficiencies for learners in grades 1 through 12. In it are listed visual arts content knowledge in the disciplines of aesthetics, art history, art criticism, and production as advocated by the discipline-based art education movement.

Based on content from the guide, the process of developing state achievement tests began. The first phase of test development resulted in creation of the Indiana State Test of Educational Progress (ISTEP). This test contains questions which address content knowledge in math, science, social studies, and language arts and is given once each year to learners in grades $1,2,3,6,8,9$, and 11. Grade level promotion for all Indiana students is based on ISTEP test scores. The ISTEP test was mandated in 1988 and is in current use throughout the state.

In 1987 researchers from the University of Illinois were contracted to conduct a state-wide survey of all public schools in Indiana, grades 1 through 12 , to assess the state of arts education. They were asked to survey content of arts curricula, availability of educational materials, scheduling and space concerns, and perceived support for arts education in the local school districts (Indiana Department of Education, 1988). Data from this research project were used to provide information about strengths and weaknesses of arts education programs which could be used to substantiate the need for 
allocation of funds to improve fine arts programs. Based on the findings of this research and on the prevailing public perceptions regarding the need for empirical data to support allocation of funds to improve educational programs, the Visual Arts Diagnostic Achievement Test Program evolved, as the next step in the developmental process of assessment in the area of visual arts.

Information contained in the Visual Arts Proficiency Guide was used to begin development of the Visual Arts Diagnostic Achievement Test Program. Visual arts diagnostic achievement tests were written and piloted during the 1987-88 school year for grades 5 and 8 . The tests are intended to be instructional and diagnostic. They provide information which helps identify curriculum strengths and deficiencies. The format for both the 5th and 8th grade tests consists of two parts. The first part contains multiple choice questions which are based on content knowledge related to art production, art history, and art criticism. This portion of the test is illustrated with examples of works of art printed in color to be used by students for reference while they are answering multiple choice questions. The second part of the test consists of a demonstration of studio production skill. Learners are asked to produce an expressive drawing which is an interpretation of a brief story that is read by the test examiner. Upon completion of this portion of the test, learners are asked to self-evaluate their drawings based on various points of reference addressing the use of the elements and principles of art. Art teachers are then asked to evaluate the learner responses to assess accuracy of student understanding of the points of reference.

Feedback from teachers in the field regarding deficiencies in the Visual Arts Proficiency Guide and from teachers involved with the piloting of the Visual Arts Diagnostic Achievement Test led to the creation of the Visual Arts Curriculum Standards Guide in 1988 (Indiana Department of Education, 1990). Creation of this guide was precipitated by comments by practitioners which suggested a need for more specific detailed curriculum development information than the Visual Arts Proficiency Guide contained. This information was necessary for the creation and revision of local visual arts curriculum guides. The Curriculum Standards Guide contains statements which suggest minimum standards of curriculum content for visual arts education. A developmental team consisting of practioners from elementary, middle, high school, and upper level education who have experience in discipline-based art education began the task of creating the guide. Content for the guide was compiled by the team based upon examination of information from various curriculum standards guides of other states, from content of the Proficiencies Guide, from analysis of content in art education texts currently accepted for adoption, from recommendations contained in reviews of literature by researchers in the art education field, and from suggestions by practioners in the field. The Visual Arts Curriculum Standards Guide was completed in 1990 and will be distributed to local school districts in 1991.

In an effort to expand the Visual Arts Diagnostic Achievement Test Program, work was begun on a third grade visual arts achievement test in 
1989. Supplied with knowledge gained from the development of the fifth and eighth grade art tests and input from participants in the pilot study of those tests, test developers made several changes in the third grade test format. The third grade test consists of three parts, all of which are read to the subjects. Part one contains multiple choice and short answer questions related to art history, art criticism, and production. Learners knowledge is examined through content which is contained in the Proficiency Guide and the Curriculum Standards Guide. Part two consists of tasks which are designed to demonstrate designated production skills levels. Learners are asked to demonstrate production skill abilities in the use of line, shape, color, texture, and form. Learners are also asked to demonstrate competencies in the use of balance, repetition, complexity, rhythm, variety, and unity. Part three consists of an expressive interpretation to an open-ended drawing problem. Learners are asked to interpret through drawing verbal suggestions given by the individual conducting the test. Evaluation of the interpretation is based on the degree to which the elements and principles are evidenced. Evaluation of the degree of expressivity is not undertaken. The Third Grade Visual Arts Diagnostic Achievement Test is currently in development with pilot testing anticipated in 1991.

\section{Issues and Concerns}

Efforts of the Department of Education in Indiana to develop evaluation instruments and procedures in academic and visual arts disciplines to assess the levels of learning being achieved in the public schools were just discussed. Inherent in the developmental process is a series of related issues and concerns. Individuals who were and are involved with this developmental process have attempted to understand and address the subtle and complex implications which these issues and concerns raise for visual art education in Indiana.

One issue related to art test development relates to the origin of the testing movement. The publication of the Nation at Risk Report and the rise of the educational excellence movement fueled the national concern with testing in the 1980s. The public demanded test scores to demonstrate evidence of the levels of learning being achieved in the public schools. Standardized tests existed which could meet the assessment needs of most academic disciplines. This, however, was not the case in the visual arts. Although there has been evidence of interest in testing in the visual arts by Manuel (1919), Meier (1929, 1942, 1963), Clark, Zimmerman, and Zurmuehlen (1987), and others, art testing has not been a major focus of research and development in the visual arts. Interest in test results to evaluate educational progress in art programs in the 1980s was externally imposed by legislators and the public on the art education field. In some cases, test results are perceived as necessary empirical evidence to prove that learning is being achieved in the art room.

Development and implementation of art tests has been met by resistance from practioners in the field. Several issues relate to this resistance. Although tests generally are understood to assess learners' levels 
of achievement, test content has acted to dictate curriculum. In this case, rather than assessing learning, tests have become sources for determining curriculum content. Art teachers and curriculum developers have thus resisted incorporation of art tests due to concerns that the use of such tests will determine art curriculum. These individuals perceive art test content as restrictive to the freedom to create and alter art curriculum to address the needs of individual learners and the development of personal expression (Clark, Zimmerman, \& Zurmuehlen, 1987). Concurrent with this issue is that of teaching performance. Test results which reflect below average performance may be interpreted as a demonstration of poor teaching ability, thereby endangering the future employment of an art teacher whose students do not achieve acceptable levels of performance on art tests. In this application, art test results may not accurately reflect the quality of instruction or motivation of teacher.

An additional issue related to art testing raises the question of whether art test results reflect the level of understanding and knowledge of the learner. In developing art tests specific content must be addressed. In the realm of art education multiple levels of understanding can be achieved. If the content of the art test does not address these levels of understanding, an inaccurate assessment of learning will result. Individual art tests cannot address all of the types of knowledge that a learner may acquire through interaction with the art curriculum. Poor art test results also may be reflective of test anxiety, inadequate test taking skills, or low reading ability.

The previous discussion suggests some negative issue related to art testing. By contrast, some issues suggest positive impact on art education programs from the use of art testing. One such issue suggests that an art testing program may provide data which can demonstrate individual growth and development. In effect, art test results can act as a yardstick by which progress can be measured and charted. Art teachers can use test results to assess student understanding of concepts. The perceptive art teacher may choose to monitor test results to determine the need for additional reinforcement of course content or to evaluate effectiveness or specific teaching methodologies.

Art test results may be used as a method of identifying strengths and weaknesses of visual arts programs. Careful analysis of art test data can indicate areas of the curriculum that need improvement or supplementation. Comparisons of test data may help chart effects of curriculum modifications. Test score records can be helpful in indicating fluctuations in the acquisition of art content. Analysis of variations in test scores may provide information that is helpful in understanding learning patterns of students.

If visual arts curriculum is structured around art history, aesthetics, art criticism, and studio production, there will be content that is specific to these disciplines. By using varieties of art tests, the art teacher can assess acquisition of knowledge that is specific to those areas of the curriculum. 
Analysis of test scores should indicate in which disciplines learner strengths and weaknesses lie, which would be helpful in determining areas of remediation.

As the test development process unfolded in the visual arts testing program of Indiana, many concerns arose that are of importance for this discussion. Although some of these concerns may be specific to the conditions of art education in Indiana, they may provide information which may be of assistance to those involved in future art test development or who are currently developing art achievement tests.

One concern addresses formulation of criteria to evaluate expressive qualities of student art work on an art test. Evaluation of personal expression is a subjective process. To establish standards of judgment for expressive quality of art work contradicts the central purpose for undertaking creative expression. To presume that standards for evaluation of expression can be identified, suggests that there are limits of acceptability for expression. If standards for personal expression were to be established, art works would become stilted and limited. Of necessity, art work would assume the characteristics of conformity. It is disturbing to imagine what the world of art would resemble, if art standards developed during some distant time frame were to act as censorship devices for artists of today. Evaluation of personal expression is equally problematic in that individuals engage in self-evaluation of art expression through an ongoing process. The establishment of personal standards of expression is an important component of art development. However, development of personal standards of expression needs to result from an informed and educated perspective and not be the result of artificially imposed standards.

Another concern related to art achievement test development is the availability of materials. All learners will not have equivalent art education resources from which to learn. Differences in exposure to visuals, quality art supplies, amounts of class time, and various other factors may contribute to creation of an extremely diverse population which art tests will be called upon to evaluate. Disparity among educational background of learners will significantly effect test results. Equally, it is problematic to create a standardized art education program which would be disseminated throughout a state or nation. Creation of a standardized art education program would once again create objectionable limitations to art educators and learners.

Attempting to create equal art education experiences is a problem compounded by the possibility that learners may not be taught by trained art education specialists. The lack of sufficient numbers of trained art specialists has led local school districts to place many individuals in art classrooms who do not have adequate art education backgrounds. It is not a valid assumption to believe that learners from these programs will have equivalent knowledge as those from programs which employ trained art education specialists. It is 
also invalid to compare test results among learners from educationally different backgrounds on a standardized art achievement test.

Unfortunately, acceptable achievement test scores may be dependent upon reading level capabilities of the learner. Frequently test results are inaccurate measures of the knowledge of the learner, due to the inability of the learner to read the test. Due to the visual nature of art, tests which assess levels of art knowledge should not be dependent upon the reading levels of learners. Art achievement tests should incorporate methods to assess art knowledge that are not entirely dependent upon reading ability. Oral and visual presentations of content for examination may facilitate a more accurate assessment of art knowledge by eliminating the extraneous variable of reading level ability.

Another major concern raised by the establishment of art achievement tests is that of determining appropriate content, vocabulary, and visual examples that will be common to all learners who will be evaluated through the art achievement test. Even though suggestions for content, vocabulary and visual examples may come from sources like a state proficiency guide or curriculum standards guide, it is questionable whether all learners will have common art knowledge. Within the field of art education debate continues about definitions of basic vocabulary and terminology. Individual interpretations and disagreement by art teachers about the meaning of references from these guides may create learners with knowledge that is dissimilar who are supposedly being exposed to similar art education curricula. Evaluating these learners, based on the interpretations of the test designers, may lead to erroneous conclusions about acquisition of knowledge. Creators of art tests that are based on references to state guidelines must assume that learners have addressed all of the content that is appropriate for a given level of achievement. This may not be a valid assumption. Art teachers, like most regular classroom teachers, will spend more time on content or areas in which they have special interests or in which they feel most competent. In so doing, insufficient time may be spent in adequately exploring all content items which may be examined on the tests. It is equally possible that art teachers may exercise discretionary judgment and eliminate content from curricula that is contained on art tests.

In the creation of an art test, developers must make judgments regarding specific skill development levels that are appropriate for a desired level of the art test. This is a central problem in the development of art achievement tests. Many tests developers do not have an adequate research base from which to gauge skill development levels or appropriate content knowledge levels for learners. The lack of research regarding art development and knowledge levels may lead to arbitrary decisions regarding content of achievement tests. Further research addressing these levels will significantly improve the content of art achievement tests and the subsequent evaluation of learners through the use of these tests. 
Testing has always been a topic of controversy regardless of subject content being tested. That problems are caused by the use of any type of evaluation procedure, is without question. However, to simply reject testing as a tool to facilitate art education because it raises problems is shortsighted. Grappling with the problems that art testing creates is a necessary component of growth and development needed in the art education field. Research in the area of art testing is necessary to find answers to questions raised by the use of visual arts achievement tests. The use of visual arts achievement tests has the potential to supply significant information about the success of art education programs, curricula, teaching methodologies, and other concerns related to art learning. The 1990 s may become the decade in which art tests become more reliable and valid and play a role in furthering learning in the visual arts.

\section{References}

Clark, G. A. (1984). Establishing reliability of a newly designed visual concept generalization test in the visual arts. Visual Arts Research, 10 (2), 73-78.

Clark, G.A., Zimmerman, E., and Zurmuehlen, M. (1987). Understanding art testing. Reston, VA: National Art Education Association.

Indiana Department of Education. (1987, June). Fine arts proficiency guide. Indianapolis, IN.

Indiana Department of Education. (1987). Indiana eighth grade diagnostic visual art achievement test. Indianapolis, IN.

Indiana Department of Education. (1987). Indiana fifth grade diagnostic visual art achievement test. Indianapolis, IN.

Indiana Department of Education. (1988). The fine arts in Indiana public schools. Indianapolis, IN: Colwell, R.

Indiana Department of Education. (1990). Indiana visual arts curriculum standards guide. Manuscript submitted for publication.

Manuel, H. T. (1919). Talent in drawing: An experimental study of the uses of tests to discover special ability. School and Home Education Monograph No. 3. Bloomington, IL: Public School Publishing Co.

Meier, N. C. $(1929,1942,1963)$. Meier art tests. lowa City, IA: State University of lowa, Bureau of Educational Research and Service. 